\title{
Sudden death and vigorous exercise-a study of 60 deaths associated with squash
}

\author{
ROBIN J NORTHCOTE, CLARE FLANNIGAN, DAVID BALLANTYNE \\ From the Department of Medical Cardiology, Victoria Infirmary, Glasgow
}

SUMMARY The circumstances surrounding 60 sudden deaths (59 men, one woman) associated with squash playing are described. The mean age (SD) of those who died was $46(10.3)$ years (range 22-66 years). Necropsy reports were available in 51. The certified cause of death was coronary artery disease in 51 cases, valvar heart disease in four, cardiac arrhythmia in two cases, and hypertrophic cardiomyopathy in one case. There were only two deaths from non-cardiac causes. Forty five of those who died had reported prodromal symptoms, the most common of which was chest pain, and 22 were known to have had at least one medical condition related to the cardiovascular system during life, the most common of which was systemic hypertension (14 subjects). Those dying from coronary artery disease had a high frequency of risk factors.

Some of these deaths might have been prevented by appropriate counselling of players after prospective medical screening, which would have detected most of the patients with overt cardiovascular disease and some of those with subclinical coronary artery disease.

The Squash Rackets Association have estimated that there may be 2.5 million people in the United Kingdom playing squash once or more a month. Squash is particularly popular with middle aged male executives and competitions have recently been expanded to include veteran and even vintage groups. Therefore a growing number of high risk individuals are being exposed to the potential hazards of a physically exhausting sport. Most previous investigation of sudden death in sport has concentrated on running ${ }^{1-3}$ and track and field sports. ${ }^{4-7}$ In 1984 we reported on 30 deaths associated with squash. ${ }^{8}$ We have continued to collate information on sudden death in squash players and we now have information on 30 additional deaths.

\section{Subjects and methods}

Because sudden death associated with sport or vigorous exercise is normally categorised only by medical cause of death it is usually not possible to obtain retrospective information on such cases. We were able to collate a series of 89 sudden deaths associated with squash that occurred between October 1976

Requests for reprints to Dr Robin J Northcote, Department of Medical Cardiology, Victoria Infirmary, Glasgow G42 9TY.

Accepted for publication 4 November 1985 and February 1984 by examining press reports and by a prospective mail survey of sports centres and squash clubs throughout the United Kingdom. The Squash Rackets Association assisted us with several cases, and a few were reported directly to us by witnesses or by officials of individual squash clubs. In 60 cases we obtained sufficient information to investigate the death in detail. In each of these cases the next of kin (usually the spouse) completed a detailed questionnaire to establish the circumstances surrounding the sudden death and the presence of premorbid symptoms or risk factors for coronary artery disease, as defined by Kannel et al. ${ }^{9}$ Prodromal symptoms were defined as any change from usual health status considered to be important by the subject and reported to relatives or friends within one week of death. ${ }^{10}$ Next of kin were invited to provide a crude assessment of the level of fitness and personality characteristics of the deceased subject. We sought permission to approach witnesses to the event and the family physician. In addition if the subject had undergone a medical examination for the purposes of employment or life insurance we asked permission to approach the appropriate authority for the results. Necropsy findings (if available) were reviewed and the results of any coroner's enquiry (England) or investigation by a procurator fiscal (Scotland) were taken into account.

Coronary artery disease was diagnosed when there 
was necropsy evidence of severe or pronounced coronary atherosclerosis (as judged by the pathologist) or when the lumen was narrowed by more than $70 \%$ with or without evidence of fresh thrombus and in the absence of other abnormalities. Pathological evidence of a healed myocardial infarction was taken to support a diagnosis of coronary artery disease.

\section{Results}

We identified 60 cases of sudden death associated with squash. They all occurred in the United Kingdom between May 1976 and April 1984. Only one of the 60 cases was female and all subjects were white. Their mean age (SD) was $46(10 \cdot 3)$ years (range 22-66 years). The Figure shows the distribution of ages.

Sudden death has been defined as death occurring within 1-24 hours of the onset of symptoms. ${ }^{11} 12$ In this study all subjects collapsed while playing squash or within an hour of playing, and all except one died within an hour of play. The remaining subject died in hospital six hours after playing. With this exception the onset of symptoms was rapid, and culminated in collapse and unconsciousness. Forty six subjects collapsed on the squash court-10 of these in the first 10 minutes of play (mean (SD) of 23 (12) minutes into play) and 14 collapsed in the first hour after play. Nine of these subjects collapsed in the first 10 minutes after exercise. Four subjects collapsed while taking a hot shower. Death was instan-

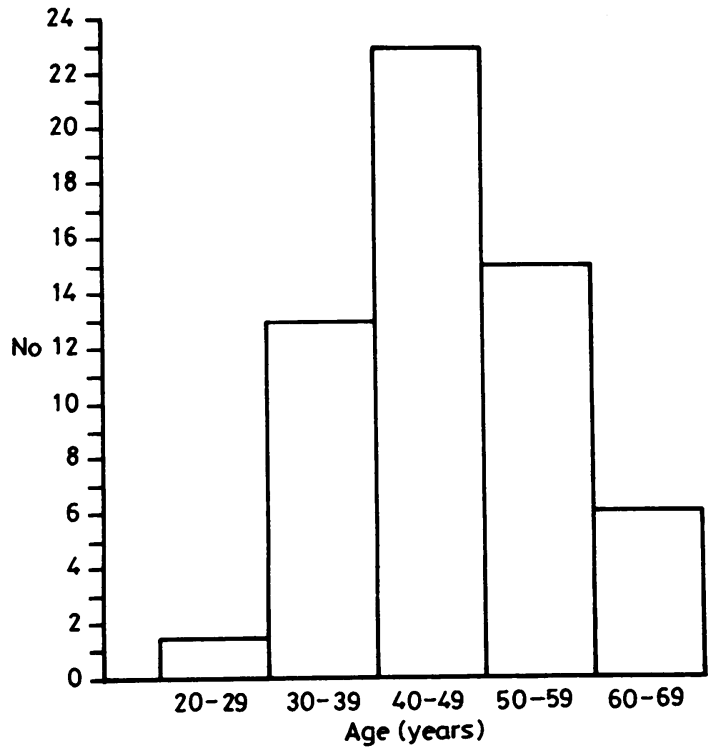

Figure Age distribution of sudden deaths associated with squash. taneous in 59 cases-the remaining subject collapsed 60 minutes after play, while driving, and died six hours later in hospital. Cardiopulmonary resuscitation was attempted in 46 cases, usually by onlookers many of whom were physicians, nurses, or first aid personnel, but defibrillation was carried out in only one case.

All the subjects had been playing squash for at least one year (mean 12 (9.7) years; range 1-40 years). In nine subjects we could not accurately determine the frequency of participation. Of the remainder, 48 players visited the court on a mean of 2.3 (1.48) times a week (range 0.25-7 times per week) to play squash and they usually played for 40-60 minutes. One subject had, on medical advice, not played squash for five years, another played only when on holiday, and one subject (aged 60 years) had recently started playing with his son after a 10 year break after medical advice to retire from the game. Sixteen subjects had started to play squash when they were over the age of 40 , whereas only 17 had been playing before the age of 30 years.

\section{CAUSE OF DEATH}

Table 1 summarises the probable causes of death. Necropsy reports were available in 51 cases. Coronary artery disease was confirmed as the cause of death in $\mathbf{4 2}$ cases in which there was severe or pronounced stenosis of at least one main coronary artery. Although 18 subjects had pathological evidence of a healed myocardial infarction, this had been diagnosed in only two cases during life. In a further two cases, however, there had been clear symptoms of prolonged anterior chest pain 10 days and four months before death. In both of these cases the pathological appearances were compatible with a myocardial infarction at these times.

In 35 cases dying of coronary artery disease a detailed description of the state of the coronary arteries was available from the necropsy report. The left anterior descending coronary artery was the single artery most often affected by atherosclerosis. There was severe triple vessel disease in 12 cases. Fresh thrombus occluded a coronary artery in nine cases. In one case (aged 22 years) the left main stem coronary artery was completely occluded by fresh thrombus in the absence of important coronary atheroma.

Table 1 Probable cause of death in 60 squash players

\begin{tabular}{lr}
\hline Cause & No \\
\hline Coronary artery disease & 51 \\
Valvar heart disease & 4 \\
Cardiac arrhythmia & 2 \\
Non-cardiac & 2 \\
Hypertrophic cardiomyopathy & 1 \\
\hline
\end{tabular}


Valvar heart disease that had been diagnosed during life caused death in four cases; none of them had been advised against physically exhausting sporting activity. At necropsy one subject (aged 26 years) with a congenitally stenotic bicuspid aortic valve was also found to have concentric left ventricular hypertrophy and irregular thickening of the valve cusps and distortion of the commisures. Another subject had congenital prolapse of the mitral valve with atrial fibrillation during life-this abnormality was confirmed at necropsy and was accompanied by pronounced left ventricular hypertrophy (heart weight $550 \mathrm{~g}$ ) in the absence of important coronary artery disease. The cause of death was certified as acute heart failure, possibly associated with a cardiac arrhythmia. ${ }^{13}$ Mitral stenosis resulting in acute heart failure was found in the second subject in the absence of important coronary artery disease. The fourth subject had a calcified aortic valve, resulting in severe aortic stenosis, and calcified coronary arteries. The certifying pathologist judged that the aortic valve lesion was the principal cause of death.

In one subject hypertrophic obstructive cardiomyopathy, a disorder known to be associated with sudden death during strenuous exercise, ${ }^{14}$ was found in the absence of other abnormalities. His family physician was not aware that he had this disorder, and annual medical examinations at work had detected no abnormality. In only two cases was death the result of non-cardiac causes. One case had a right intracranial haemorrhage, and symptoms developed 60 minutes after this subject had finished playing squash. He died in hospital 6 hours later without regaining consciousness. The other subject had played squash soon after a heavy meal and at necropsy both lungs were found to be collapsed as a result of aspiration of stomach contents. There was no evidence of heart disease in either case. In two cases, no abnormality was found at necropsy and the certifying pathologist judged that death in both had resulted from a cardiac arrhythmia. This diagnosis should ideally be supported by a thorough histopathological examination of the conduction system of the heart. ${ }^{15}$ This was carried out in a specialist centre in one case, but no abnormality was detected. Since both deaths were instantaneous it seems likely that the certified cause of death was correct.

All of the nine cases in which necropsy was not performed were certified as having died of coronary artery disease. In five cases there were no clearly distinguishable features apart from the sudden collapse to support this diagnosis. Thirty minutes before death one subject complained of cardiac pain to his physician. Since this was accompanied by sweating, coronary artery disease was likely to have been the cause of death. Two subjects had a history of previous myocardial infarction and one of these had also had documented aortic regurgitation in the 10 years before death. A further subject had a history of angina pectoris one year before death and had important ST segment depression on exercise electrocardiography. In each of these nine cases the certifying doctor judged that coronary artery disease was the cause of death.

PREMORBID CONDITIONS AND SYMPTOMS Forty five subjects had reported at least one prodromal symptom within one week of their sudden death, and 16 subjects had reported more than one symptom (Table 2). Only nine were known to have consulted their family physician about these symptoms, although a further two had arranged appointments with their practitioner.

Twenty two subjects were known to have had at least one medical disorder during life related to the cardiovascular system; 14 had hypertension documented on two or more occasions. Only two subjects, however had been on antihypertensive medication. Excluding hypertension, 14 subjects had medical conditions known to themselves and their family physician that were relevant to the cardiovascular system (Table 3).

Of the 51 subjects dying of coronary artery disease, 32 had at least one risk factor, 15 had two, and five had three or more (Table 4).

\section{PERCEPTION OF PHYSICAL FITNESS}

Next of kin were requested to assess the physical fitness of the deceased in relation to the general population in five categories ranging from very fit to very unfit. No subject was considered to be unfit, whereas 32 of the group were considered to be very fit, 22 fit, and only six were considered to be of average fitness.

\section{Table 2 Prodromal symptoms}

\begin{tabular}{|c|c|}
\hline Symptom & No \\
\hline $\begin{array}{l}\text { Chest pain/angina } \\
\text { Increasing fatigue } \\
\text { Indigestion/heart burn/gastrointestinal symptoms } \\
\text { Excessive breathlessness } \\
\text { Ear or neck pain } \\
\text { Vague malaise } \\
\text { Upper respiratory tract infection } \\
\text { Dizziness/palpitation } \\
\text { Severe headache } \\
\text { None }\end{array}$ & $\begin{array}{l}15^{\star} \\
12 \\
10 \\
6 \dagger \\
5 \\
5 \\
4 \\
3 \\
2 \ddagger \\
5\end{array}$ \\
\hline \multicolumn{2}{|c|}{$\begin{array}{l}\text { \# One subject, an international squash player, had recently } \\
\text { consulted a physician because of chest pain after squash play. } \\
\text { +One subject, who ran one mile every morning, was extremely } \\
\text { breathless on three successive mornings before he died, but was not } \\
\text { deterred from further strenuous exertion. } \\
\text { † Cause of death in one subject was intracranial haemorrhage. }\end{array}$} \\
\hline
\end{tabular}


e 3 Clinical and demographic findings in subjects known to have medical conditions

\begin{tabular}{|c|c|c|c|c|c|c|}
\hline Age & $\begin{array}{l}\text { Years playing } \\
\text { squash }\end{array}$ & Frequency & Clinical diagnosis & Symptoms & Risk factors & Cardiac pathology \\
\hline 52 & 5 & 1 & $\begin{array}{l}\text { Two previous } \\
\text { myocardial } \\
\text { infarctions, MODM }\end{array}$ & Nocturnal angina & Diabetes & $\begin{array}{l}\text { Healed myocardial } \\
\text { infarction, } R+L \text { CA } \\
\text { occlusion }\end{array}$ \\
\hline 69 & 35 & 2 & $\begin{array}{l}\text { IHD, previous CABG, } \\
\text { internal pacemaker }\end{array}$ & General malaise & Smoking & $\begin{array}{l}\text { Healed myocardial } \\
\text { infarction, 3-vessel } \\
\text { disease }\end{array}$ \\
\hline 26 & 3 & 1 & Aortic stenosis & $\begin{array}{l}\text { Flu-like symptoms } 1 \\
\text { week }\end{array}$ & - & $\begin{array}{l}\text { Bicuspid aortic valve, } \\
\text { concentric LV } \\
\text { hypertrophy }\end{array}$ \\
\hline 65 & 35 & $\begin{array}{l}1 \text { st match in } 5 \\
\text { years }\end{array}$ & $\begin{array}{l}\text { Previous myocardial } \\
\text { infarction }\end{array}$ & Fatigue & $\begin{array}{l}\text { Smoking, } \\
\text { hypertension }\end{array}$ & Not available \\
\hline 44 & 3 & $2-4$ & IHD & Angina pectoris & $\begin{array}{l}\text { Smoking, family } \\
\text { history }\end{array}$ & $\begin{array}{l}\text { 3-vessel disease, } \\
\text { thrombus occluding } \\
\text { RCA }\end{array}$ \\
\hline 51 & 25 & $3-4$ & Atypical chest pain & Chest pain & Family history & $\begin{array}{l}\text { Healed myocardial } \\
\text { infarction, 3-vessel } \\
\text { disease }\end{array}$ \\
\hline 43 & 2 & 2 & Gastritis & $\begin{array}{l}\text { Dyspepsia, chest pain, } \\
\text { malaise }\end{array}$ & - & $\begin{array}{l}\text { Myocardial infarction, } \\
10 \text { days old, LV } \\
\text { hypertrophy, } \\
\text { 3-vessel disease }\end{array}$ \\
\hline 62 & 30 & 3 & Atrial fibrillation & $\begin{array}{l}\text { Previous collapse at } \\
\text { squash, malaise }\end{array}$ & - & $\begin{array}{l}\text { Healed myocardial } \\
\text { infarction, 3-vessel } \\
\text { disease }\end{array}$ \\
\hline 39 & 10 & 7 & $\begin{array}{l}\text { Subarachnoid } \\
\text { haemorrhage } 17 \mathrm{yr}\end{array}$ & & Smoking & LAD occlusion \\
\hline 54 & 2 & $1-2$ & IHD & Angina pectoris & $\begin{array}{l}\text { Smoking, } \\
\text { hyperlipidaemia }\end{array}$ & Not available \\
\hline 66 & $\begin{array}{l}\text { Return after } 10 \\
\text { year lay-off }\end{array}$ & $1-2$ & $\begin{array}{l}\text { Atrial fibrillation } \\
\text { mitral valve prolapse }\end{array}$ & Dyspnoea & Family history & $\begin{array}{l}\text { Mitral valve prolapse } \\
\text { large dilated heart } \\
(550 \mathrm{~g})\end{array}$ \\
\hline 32 & 6 & 1 & $\begin{array}{l}\text { Previous myocardial } \\
\text { infarction, aortic } \\
\text { incompetence }\end{array}$ & - & $\begin{array}{l}\text { Smoking, } \\
\text { hyperlipidaemia, } \\
\text { hypertension }\end{array}$ & 一 \\
\hline 45 & 12 & $3-4$ & Mitral stenosis & 一 & Family history & $\begin{array}{l}\text { LV hypertrophy, } \\
\text { severe } \\
\text { mitral stenosis, } \\
\text { moderate CHD }\end{array}$ \\
\hline 52 & 4 & 3 & $\begin{array}{l}\text { Two previous } \\
\text { myocardial } \\
\text { infarctions, MODM }\end{array}$ & - & $\begin{array}{l}\text { Smoking, } \\
\text { hypertension, } \\
\text { diabetes }\end{array}$ & - \\
\hline
\end{tabular}

BG, coronary artery bypass graft; IHD, ischaemic heart disease; L, left; LAD, left anterior descending coronary artery; LV, left ventricule; JDM, maturity onset diabetes mellitus; $R$, right.

PERSONALITY AND PSYCHOLOGICAL INFLUENCES

Many players had clearly ignored prodromal symptoms and known medical conditions and had continued to play squash. Next of kin were asked to describe the deceased's predominant personality characteristics. Twelve subjects were considered to be competitive, ambitious, hard driving, and per-

Table 4 Risk factors for coronary heart disease in 51 subjects dying of coronary heart disease

\begin{tabular}{ll}
\hline Risk factor & No \\
\hline Smoking (>10 cigarettes/day) & 25 \\
Family history of early myocardial infarction & 18 \\
$\quad$ (<55 years) & 14 \\
Hypertension & 8 \\
Angina/previous myocardial infarction & 3 \\
Hypercholesterolaemia & 2 \\
Diabetes mellitus & \\
\hline
\end{tabular}

fectionist, 13 were thought to be very aggressive, two to be very competitive, and one to be obsessive about fitness. One subject was described as eccentric. Only four were thought to be passive. In 27 no clearly recognisable traits could be identified.

Psychological or emotional stress might have contributed to death in four cases. The most extreme case was that of a man of 26 with a congenitally stenotic aortic valve who collapsed and died on the court minutes after breaking his opponent's jaw.

\section{OCCUPATION}

Many of the people in this study had professional or executive jobs. Fourteen were company directors, nine worked in higher education (two university professors and seven lecturers), four were civil servants, one was a physician, four were engineers, and one was a school teacher. The remainder worked in various other occupations only two of which would be regarded as non-sedentary. 


\section{Discussion}

These data confirm that coronary artery disease is responsible for most cases of sudden death associated with vigorous sport. The results in the age group of subjects that we studied accord with those of other studies that examined sudden death in sport. $^{1-5}$ In particular, a recent study of 30 deaths in joggers reported a similar frequency of coronary artery disease and necropsy evidence of healed or acute myocardial infarction. ${ }^{3}$ The authors of this report also remarked on the high frequency of coronary artery disease risk factors in their group. Another study of nine joggers demonstrated a high frequency of premorbid cardiovascular conditions (that is previous myocardial infarction, angina, hypertension, diabetes), ${ }^{16}$ in keeping with our results, and the authors suggested that the deaths might have been delayed had the subjects participated in less strenuous exercise. Hypertrophic obstructive cardiomyopathy may be responsible for about half the sudden deaths in a youthful athletic population during sport, ${ }^{17}$ but we identified only one such case (aged 38 years). Less common causes of sudden death during physical activity have been described, including myocarditis ${ }^{18}$ and fibromuscular dysplasia of the sinus or atrioventricular node artery. ${ }^{15}$ Such abnormalities might be missed during routine necropsy examination. ${ }^{19}$ In two of our cases no gross pathological abnormality was found to explain the sudden death, in one of these cases a detailed histopathological examination performed at a special centre showed no abnormality. The cause of death in these cases is a matter for speculation, although a cardiac arrhythmia seems to be the most likely cause of death.

The most frequent pathological lesion was severe stenosis of at least one major coronary artery; a fresh occlusive thrombus was present in only $18 \%$ of cases. A recent study of 100 sudden cardiac deaths by Davies and Thomas, showed that $44 \%$ of cases had major fresh thrombus occluding more than $50 \%$ of the cross sectional area of the coronary vessels. ${ }^{20}$ In our study the coroner's routine necropsy may not have detected thrombi that would have been found by a prospective detailed study of coronary vasculature. Alternatively, it is possible that coronary artery occlusion can occur without thrombus formation during vigorous exercise, perhaps as a result of coronary artery spasm.

Sudden cardiac death is usually caused by ventricular fibrillation or asystole. Such events may be more likely during vigorous exercise in subjects with coronary artery disease, because oxygen demand may outstrip the ability of the coronary arteries to supply it. It is also possible that metabolic influences associated with exercise may precipitate or contribute to an arrhythmia. For example, free fatty acid and catecholamine concentrations may rise during exercise ${ }^{21}$ and this can cause arrhythmias ${ }^{22}$ and arterial thrombosis ${ }^{23}$ especially in the presence of coronary artery stenosis. ${ }^{24}$ These changes, together with exercise-induced lactic acidosis, ${ }^{25}$ and hyperkalemia ${ }^{26}$ may also help to explain the failure of cardiopulmonary resuscitation. In this study we were impressed by the large number of cases in which cardiopulmonary resuscitation had been attempted by trained personnel, and, as we have no data on survivors, this leads us to suspect an underestimation of the frequency of cardiac events during squash.

We cannot say whether these subjects would have survived for longer if they had not exercised so vigorously. We suspect, however, that myocardial infarction is more likely to cause sudden death when it occurs during vigorous exercise. This suggestion is supported by the Framingham study ${ }^{27}$ and by a British report examining the circumstances surrounding 100 sudden deaths from coronary artery disease. ${ }^{28}$ Friedman et al found that individuals dying instantly, as in this study, were significantly more likely to have been engaging in severe or moderate exertion just before death and usually had severe coronary artery disease which precipitated cardiac arrhythmias. ${ }^{12}$ We have previously demonstrated that squash is capable of raising heart rate to $90 \%$ of predicted maximum for extended periods and of generating importaint cardiac arrhythmias in a young normal population. ${ }^{29}$ This may indicate that squash is an inappropriate sport for those with coronary artery disease or other cardiac disease or even those whose age puts them at increased risk of coronary disease.

Many individuals in this study with known medical conditions continued to play squash. Men in middle age seem reluctant to acknowledge that they may be in poor physical condition or health. $\mathrm{We}^{8}$ and others ${ }^{24}$ have noted that sportsmen tend to deny physical infirmity and prodromal symptoms. In this study 22 subjects had known cardiovascular disease and $75 \%$ had complained of at least one prodromal symptom but apparently had not sought medical advice. These people may not have recognised the importance of their symptoms. People with recognised cardiovascular disease should be warned by their physicians not to take part in vigorous physically exhausting exercise although more gentle exercise may be beneficial.

In addition to a tendency to ignore prodromal symptoms and pre-existing disease at least half of the subjects in this series may have been type A personalities, and this in itself may have increased their 
risk of sudden death and the development of coronary heart disease. ${ }^{30} 31$ Acute psychological stress, which both Engel ${ }^{32}$ and Lown ${ }^{33}$ believe can precipitate lethal cardiac arrhythmias, was present in four cases. The mechanism by which type $A$ behaviour contributes to sudden death is unknown.

Although the risk of sudden death during squash is small the number of deaths associated with the game is appreciable. Although this may merely reflect the popularity of the game it is just as likely to reflect its strenuous and demanding nature, which clearly makes it unsuitable for those with cardiovascular disease. The preponderance of men in this study may indicate their greater participation in the sport at an age when they are at increased risk of coronary artery disease.

It is not our object to condemn squash as a recreation, rather we aim to draw attention to areas in which its safety may be improved and with it the enjoyment of playing. We congratulate the Squash Rackets Association for forming a medical study group in 1980 to monitor the situation and for circulating a list of precautions to prospective players in all their affiliated clubs.

We hope that reports such as this one will increase the awareness of both the public and the medical profession of the dangers of exhausting exercise in unsuitable subjects.

We thank the Squash Rackets Association, the Coroners Society (England), and Crown Office (Scotland) for their help in collation of data; and the relatives and general practitioners for their cooperation. The study was supported by a grant from the Chest, Heart and Stroke Association.

\section{References}

1 Waller BF, Roberts WC. Sudden death while running, in conditioned runners aged 40 years or over. Am $\mathcal{F}$ Cardiol 1980; 45: 1292-1300.

2 Thompson PD, Stern MP, Williams P, Duncan K, Haskell W, Wood $P$. Death during jogging or running: a study of 18 cases. fAMA 1979; 242: 1265-7.

3 Vermani R, Robinowitz M, McAllister HA. Nontraumatic death in joggers. A series of 30 patients at autopsy. Am $\mathcal{~}$ Med 1982; 72: 874-82.

4 Opie LH. Sudden death and sport. Lancet 1975; i: 263-6.

5 Lynch P. Soldiers, sport and sudden death. Lancet 1980; i: 1235-7.

6 Maron BJ, Roberts WC, McAllister HA, Rosing DR, Epstein SE. Sudden death in young athletes. Circulation 1980; 60: 218-29.

7 Northcote RJ, Ballantyne D. Sudden cardiac death in sport. $\mathrm{Br}$ Med f 1983; 287: 1357-9.

8 Northcote RJ, Evans ADB, Ballantyne D. Sudden death in squash players. Lancet 1984 ; i: $148-51$.
9 Kannel WB, Doyle JT, McNamara PM, Quikenton P, Gordon $T$. Precursors of sudden coronary death. Factors related to the incidence of sudden death. Circulation 1975; 51: 606-13.

10 Alonzo AA, Simon AB, Feinlab M. Prodromata of myocardial infarction and sudden deaths. Circulation 1975; 52: 1056-62.

11 Kuller L, Lillienfield A, Fisher R. An epidemiological study of sudden and unexpected deaths in adults. Medicine (Baltimore) 1967; 46: 341-61.

12 Friedman M, Manaaring JH, Rosenman RH, Donlon G, Ortega P, Grube SM. Instantaneous and sudden deaths: clinical and pathological differentiation in coronary artery disease. JAMA 1973; 225: 1319-28.

13 Mills P, Rose J, Hollingsworth J, Amara I, Craige E. Longterm prognosis of mitral valve prolapse. $N$ Engl $f$ Med 1977; 297: 13-8.

14 Maron BJ, Roberts WC, Edwards JE, McAllister HA, Foley DD, Epstein SE. Sudden death in patients with hypertrophic cardiomyopathy: characterisation of 26 patients without previous functional limitation. Am $\mathcal{F}$ Cardiol 1978; 41: 803-10.

15 James TN, Froggatt P, Marshall TK. Sudden death in young athletes. Ann Intern Med 1967; 67: 1013-21.

16 Jackson RT, Beaglehole R, Sharpe N. Sudden death in runners. NZ Med F 1983; 96: 289-92.

17 Maron BJ, Epstein SE, Roberts WC. Hypertrophic cardiomyopathy: a common cause of sudden death in the young competitive athlete. Eur Heart f 1983; 4 (suppl F): 135-44.

18 Barlow JB. Exercise, rugby football and infection. $S$ Afr Med $\mathcal{F}$ 1976; 50: 1351 .

19 Rossi L, Thieve G. Recent advances in clinical histopathologic correlates of sudden cardiac death. Am Heart $f$ 1981; 102: 478-84.

20 Davies $M J$, Thomas $A$. Thombosis and acute coronary artery lesions in sudden cardiac ischaemic death. $N$ Engl F Med 1984; 310: $1137-40$.

21 Johnson RH, Walton JL, Krebs HA, Williamson DM. Metabolic fuels during and after severe exercise in athletes and nonathletes. Lancet 1969; ii: 452-5.

22 Kurien VA, Yates PA, Oliver MF. The role of free fatty acids in the production of ventricular arrhythmias after acute coronary artery occlusion. Eur $\mathcal{F}$ Clin Invest 1971; 1: 225-41.

23 Hoak JC, Poole JCF, Robinson DS. Thrombosis associated with mobilisation of fatty acids. Am F Pathol 1963; 43: 987-98.

24 Raab W, Van Lith P, Lepeschin E, Herrlich HC. Catecholamine induced myocardial hypoxia in the presence of impaired coronary dilatability independent of external cardiac work. Am f Cardiol 1962; 9: 455-70.

25 Bouhuys A, Poole J, Binhorsl RA, et al. Metabolic acidosis of exercise in healthy males. I Appl Physiol 1966; 21: 1040-6.

26 Linton RAF, Lim M, Wolf CB, Wilmhurst P, Band DM. Arterial plasma potassium measured continuously during exercise in man. Clin Sci 1984; 67: 427-31.

27 Kannel WB, Thomas HE Jr. Sudden coronary death: the Framingham study. Ann NY Acad Sci 1982; 382: 3-21.

28 Myers A, Dewar HA. Circumstances attending 100 sudden deaths from coronary artery disease with coroner's necropsies. Br Heart I 1975; 37: 1133-43.

29 Northcote RJ, MacFarlane P, Ballantyne D. Ambulatory electrocardiography in squash players. Br Heart $\mathcal{F} 1983$; 50: 372-7.

30 Review Panel on Coronary-Prone Behaviour and Coronary Heart Discase. Coronary-prone behaviour and coronary heart disease: a critical review. Circulation 1981; 63: 1199-215.

31 Chesney MA, Rosenman RH. Type A behaviour, observations on the past decade. Heart Lung 1982; 11: 12-9.

32 Engel GL. Sudden and rapid death during psychological stress. Folklore or folk wisdom? Ann Intern Med 1971; 74: 771-82.

33 Lown B. Mental stress, arrhythmias and sudden death. $A m \mathcal{F}$ Med 1982; 72: 177-80. 